\title{
A pattern of poisoning in children- an experience from a teaching hospital in southern India
}

\author{
Vijayalakshmi $\mathbf{P}^{\mathbf{1}}$, V. Benakanal S. ${ }^{2 *}$, B. Patil R. ${ }^{3}$, Manoj GM ${ }^{4}$, S. Kumar R. ${ }^{5}$ \\ DOI: https://doi.org/10.17511/ijpr.2020.i06.09
}

${ }^{1}$ Vijayalakshmi P, Assistant Professor, Department of Paediatrics, SHIMOGA Institute of Medical Sciences, Shivamogga, Karnataka, India.

2* Shreeshail V. Benakanal, Assistant Professor, Department of Paediatrics, SHIMOGA Institute of Medical Sciences, Shivamogga, Karnataka, India.

${ }^{3}$ Ravindra B. Patil, Professor and HOD, Department of Paediatrics, SHIMOGA Institute of Medical Sciences, Shivamogga, Karnataka, India.

${ }^{4}$ Manoj GM, Senior resident, Department of Paediatrics, SHIMOGA Institute of Medical Sciences, Shivamogga, Karnataka, India.

${ }^{5}$ R. Vikram S. Kumar, Professor, Department of Pediatrics, Subbaih Institute of Medical Sciences, Shivamogga, Karnataka, India.

Introduction: Poisoning in children is an important Paediatric emergency and is a worldwide problem. It is a common and preventable cause of morbidity and mortality in children. Objectives: The aim of this study was to determine the profile and outcome of children less than 13 years admitted to the Paediatric department presenting with acute poisoning at a Teaching district hospital in southern Karnataka. Methods: Prospectively, 134 acute poisoning cases, admitted to Paediatric intensive care, SIMS Shivamogga from November 2018 to May 2019 were included in this study. Results: During the study period, 134 patients presented with acute poisoning. The incidence of poisoning in Paediatric patients was $2.84 \%$. The median age of our patients was 5.2 years (range $0.75-12$ years). The male to female ratio was $1.58: 1$. Animal bites $(27.61 \%)$, Petroleum products $(26.87 \%)$, Household chemicals $(15.67 \%)$, Drugs $(11.19 \%)$, Poisonous plant derivatives $(8.96 \%)$ and Insecticides $(6.72 \%)$ were the agents most frequently implicated. Almost all $(98.41 \%)$ cases in 1 to 5 years age group were accidental in nature, whereas in the $>10$ years age group, the majority $(71.43 \%)$ were suicidal. Thirteen patients $(9.7 \%)$ remained asymptomatic. The specific antidote was given to $19(14.18 \%)$ patients. Three patients ( 2 snake bite and 1 rodenticide child) died. The mean duration of hospital stay was 4.49 days (range was 1 day to 22 days). Conclusions: Accidental poisoning was common in children below 5 years of age. Minimal age of suicidal poisoning was 8 years. The most common agent implicated was a snake bite.

Keywords: Acute poisoning, Profile, Snakebite, Kerosene, Turpentine

\section{Corresponding Author}

Shreeshail V. Benakanal, Assistant Professor, Department of Paediatrics, SHIMOGA Institute of Medical Sciences, Shivamogga, Karnataka, India. Email: shreeben@gmail.com

\section{How to Cite this Article}

Vijayalakshmi P, Shreeshail V B, Ravindra B P, Manoj GM, Vikram RKS. A pattern of poisoning in childrenan experience from a teaching hospital in southern India. Pediatric Rev Int J Pediatr Res. 2020;7(6):279-286.

Available From

https://pediatrics.medresearch.in/index.php/ijpr/arti cle/view/615
To Browse

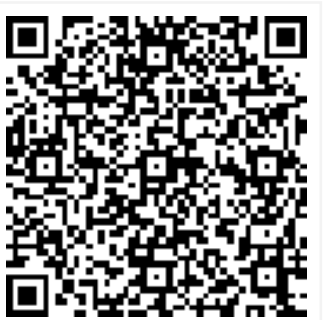

Manuscript Received 2020-08-03

Conflict of Interest No
Review Round 1 2020-08-18

Funding

Review Round 2
2020-08-24
Ethical Approval
Yes

Review Round 2

Yes
Review Round 3

Accepted 2020-08-26

Plagiarism X-checker $7 \%$ (C) 2020 by Vijayalakshmi P, Shreeshail V. Benakanal, Ravindra B. Patil, Manoj GM, R. Vikram S. Kumar and Published by
Siddharth Health Research and Social Welfare Society. This is an Open Access article licensed under a Creative Commons Attribution 4.0 International License https://creativecommons.org/licenses/by/4.0/ unported [CC BY 4.0]. 


\section{Introduction}

Poisoning is an important emergency as well as a major problem in all age groups throughout the world. The cause and poisoning type varies in different parts of the world and within the country also depending upon factors such as education, demography, socioeconomic factors, customs, and local belief [1].

The most recent estimate of the World Health Organization (WHO) suggests 180 thousand deaths in 2010 due to various poisoning agents [2]. Poisoning account for $1-6 \%$ of bed occupancy in children hospitals and $3.9 \%$ in the pediatric intensive care unit in India $[3,4,5]$. Poisoning is predominantly accidental particularly in $<5$ years but might be increasingly self-inflicted in older children [6]. Approximately 2 million people each year under 6 years come to the emergency department with a history of poisoning [7]. Accidental poisoning is the twelfth leading cause of admission in the pediatric ward in India and accounts for about $1.0 \%$ of the hospitalized patients [8]. Sometimes exposure to the non-poisonous substance or suspected poisoning necessitates hospitalization and an increased burden to the hospital [9].

The pattern of Poisoning varies according to age, the nature, and dose of the poison and type of exposure [10]. Among the accidental poisoning, even though there is no significant decrease in the number, the pattern of poisoning has shown a change with new hazards constantly appearing due to the introduction of newer drugs and chemicals for domestic use, farming [11]. Therefore, a periodic review of current data on poisoning from various centers is essential for providing the ever-changing information [12]. With increasing urbanization and rapid socio-economic development in India during the last two decades, some change in pediatric poisoning profile and outcome is to be expected. Understanding about nature and severity of poisoning is crucial for appropriate and effective management. General epidemiological data should be used to assist the emergency department on proper management of poisoning cases especially for effective preventive and therapeutic approaches [13].

No previous studies have been done on acute poisoning in children at our center. The present study was carried out in the department of
Pediatrics of District Hospital, which is catering services to this entire district, including parts of neighboring districts with the aim of determining the profile and outcome of children presenting with acute poisoning and bites.

\section{Material and Methods}

Setting-The present study was a Prospective observational study conducted in the Department of Paediatrics, SIMS, McGann District teaching hospital, Shivamogga.

Duration of study -The study was done between November 2018 to May 2019.

Sample size and inclusion criteria- All children below 13 years of age, who were admitted to the SIMS pediatric intensive care unit with a history of poisoning were included in this study. A total of 134 cases were admitted to an emergency with a history of poisoning during this period.

Exclusion criteria- Patients without a history of poisoning were excluded from the study.

Data collection procedure - The study was conducted after obtaining verbal and written consent from the parent or guardian. These cases were admitted to Paediatric intensive care after the initial assessment. Data regarding the age of the patient, sex, nature of poisoning (accidental or intentional), the time when poison was ingested or had come in contact with it, the substance is taken, its dose, cause for poisoning, any intervention has done before reaching our hospital and time brought to casualty, clinical presentation, detailed general physical examination, systemic examination, duration of hospital stay and outcome were collected and filled in a predesigned Performa.

Ethical consideration and permissionInstitutional ethical committee permission was obtained.

Statistical Analysis- The data collected were then transferred into excel format and analyzed as percentages. The current study analyzed the data using SPSS 26. For statistical analysis, Fisher's exact $\mathrm{X} 2$ test was used where appropriate and a $\mathrm{p}$ value less than 0.05 were taken to be significant.

\section{Results}

Our centre is 950 bedded district teaching hospital. During the study period, the total number of patients admitted was 44012 , the total number of 
Pediatric patients was 4722, and total cases admitted to PICU were 336. Out of these 134 cases came with a history of poisoning. This accounts for $39.88 \%$ of PICU admission during this period. The
Incidence of poisoning in pediatric patients was $2.84 \%$. Males accounted for $61.2 \%$ (82 cases) and 52 cases were females accounting for $38.8 \%$, with male to female ratio of 1.58 .

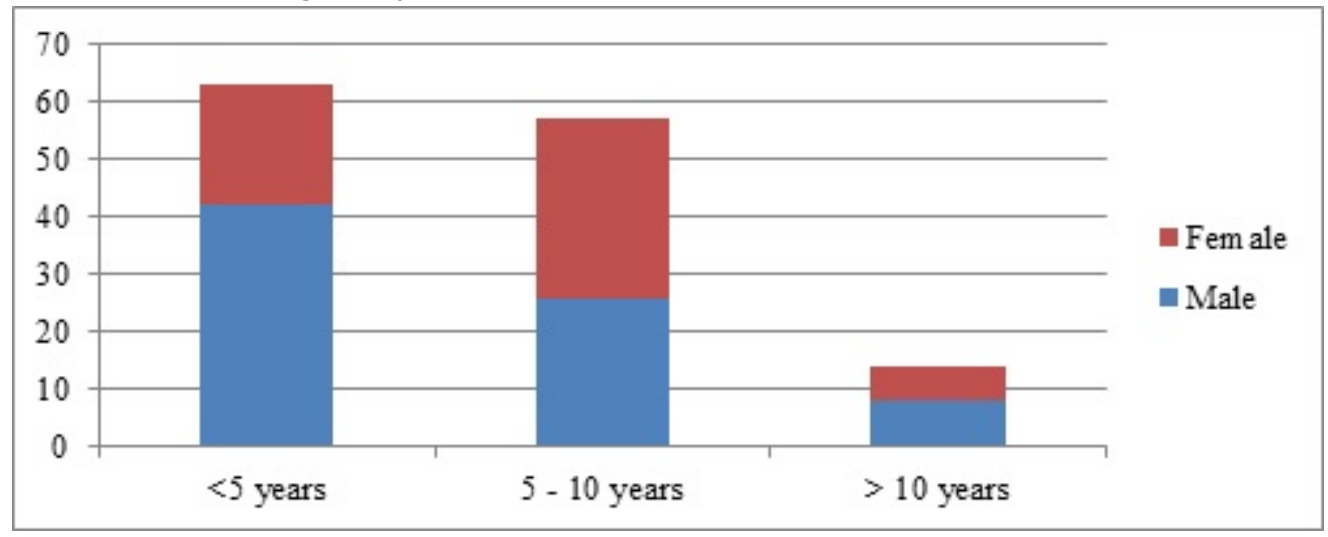

Fig-1: Age and sex distribution.

The median age of our patients was 5.2 years (range $0.75-12$ years). The majority of cases were below 5 years (63 cases, 47.01\%), followed by 5-10 years age group (57 cases, 42.54\%) and least was above 10 years (14 cases, 10.45\%). Age and sex distribution are shown in Figure 1 . Table 1 demonstrates the details of poisoning agents.

Table -1: Types and mode of acute poisoning along with age-wise distribution.

\begin{tabular}{|c|c|c|c|c|c|c|c|}
\hline Poisoning agent & Type of poison & No. of cases & N $(\%)$ & $<5$ years $N(\%)$ & $5-10$ years $N(\%)$ & $>10$ years $\mathrm{N}(\%)$ & Urban/ Rural \\
\hline \multicolumn{8}{|c|}{ Bites and stings } \\
\hline \multirow[t]{4}{*}{ Snakebite } & Unknown species & 9 & \multirow[t]{8}{*}{$37(27.61 \%)$} & \multirow[t]{8}{*}{$9(6.7 \%)$} & \multirow[t]{8}{*}{$24(17.9 \%)$} & \multirow[t]{8}{*}{$4(2.9 \%)$} & \multirow[t]{8}{*}{$14 / 23$} \\
\hline & Cobra & 8 & & & & & \\
\hline & Viper & 3 & & & & & \\
\hline & Krait & 3 & & & & & \\
\hline \multicolumn{3}{|l|}{ Unknown bite } & & & & & \\
\hline \multicolumn{3}{|l|}{ Bee sting } & & & & & \\
\hline \multicolumn{3}{|l|}{ Scorpion sting } & & & & & \\
\hline \multicolumn{2}{|l|}{ Lizard cont food } & 3 & & & & & \\
\hline Petroleum products & $\begin{array}{l}\text { Kerosene } \\
\text { Turpentinepaint thinner } \\
\text { Petrol } \\
\text { Diesel }\end{array}$ & $\begin{array}{l}13 \\
18 \\
2 \\
3\end{array}$ & $36(26.87 \%)$ & $26(19.4 \%)$ & $10(7.4 \%)$ & - & $17 / 19$ \\
\hline \multirow[t]{7}{*}{ Household chemicals } & Phenol & 5 & \multirow[t]{7}{*}{$21(15.67 \%)$} & \multirow[t]{7}{*}{$9(6.7 \%)$} & \multirow[t]{7}{*}{$10(7.4 \%)$} & \multirow[t]{7}{*}{$2 *(1.4 \%)$} & \multirow[t]{7}{*}{$14 / 7$} \\
\hline & Unknown liquid & 6 & & & & & \\
\hline & Machine lubricant & 1 & & & & & \\
\hline & Rubber milk & 1 & & & & & \\
\hline & Aquarium beads & 1 & & & & & \\
\hline & Red oxide for flooring & 1 & & & & & \\
\hline & Chalk, Calcium carbonate & 1 & & & & & \\
\hline \multirow[t]{3}{*}{ Drugs (tablets) } & Clonazepam & 5 & \multirow[t]{8}{*}{$15(11.19 \%)$} & \multirow[t]{8}{*}{$10(7.4 \%)$} & \multirow[t]{8}{*}{$5(3.7 \%) 1$-suicidal } & & \multirow[t]{8}{*}{$7 / 8$} \\
\hline & Phenytoin & 1 & & & & & \\
\hline & Unknown & 2 & & & & & \\
\hline \multirow[t]{5}{*}{ Drugs (Liquid preparations) } & Betadine solution & 2 & & & & & \\
\hline & $10 \%$ salicylic acid & 1 & & & & & \\
\hline & Lindane solution & 1 & & & & & \\
\hline & Ear drops for wax & 1 & & & & & \\
\hline & Alcohol & 2 & & & & & \\
\hline
\end{tabular}




\begin{tabular}{|c|c|c|c|c|c|c|c|}
\hline \multirow[t]{3}{*}{ Plant derivatives } & White sapota/ Mexican apple (Casimiroa edulis) & 2 & \multirow[t]{3}{*}{$12(8.96 \%)$} & \multirow[t]{3}{*}{$8(5.9 \%)$} & \multirow[t]{3}{*}{$4(2.9 \%)$} & \multirow[t]{3}{*}{-} & \multirow[t]{3}{*}{$0 / 12$} \\
\hline & Jatropha curcas seeds & 8 & & & & & \\
\hline & Unknown seeds & 2 & & & & & \\
\hline \multirow[t]{4}{*}{ Insecticides, pesticides } & Organophosphates & 4 & \multirow[t]{4}{*}{$9(6.72 \%)$} & \multirow[t]{4}{*}{$1 * *(1.4 \%)$} & \multirow[t]{4}{*}{$3(2.2 \%),(1 * *)$} & \multirow[t]{4}{*}{$5 *(3.7 \%)$} & \multirow[t]{4}{*}{$1 / 8$} \\
\hline & Ant powder ( $1 \%$ cypermethrin) & 2 & & & & & \\
\hline & Lakshman rekha (herbal) & 1 & & & & & \\
\hline & Ratol (3\% yellow phosphorous) & 2 & & & & & \\
\hline \multirow[t]{2}{*}{ Herbicides } & Roundup (Glyphosate 54\%) & 3 & \multirow[t]{2}{*}{$4(2.98 \%)$} & \multirow[t]{2}{*}{-} & \multirow[t]{2}{*}{$1 *(1.4 \%)$} & \multirow[t]{2}{*}{$3 *(2.2 \%)$} & \multirow[t]{2}{*}{$0 / 4$} \\
\hline & Mancozeb & 1 & & & & & \\
\hline
\end{tabular}

*Suicidal **Homicidal

Almost all cases (120 cases, 89.55\%) were accidental, 12 cases $(8.96 \%)$ were suicidal and 2 cases were homicidal (parents consumed poison and fed the same to children). Minimal age of suicidal poisoning in the present study was 8 years. Majority of the cases $(82,61.19 \%)$ reached within 1 to 4 hours, 21 cases (15.67\%) reached within 1 hour of consumption, 23 cases $(17.16 \%)$ reached between 4-12 hours and 8 cases (5.97\%) reached after 12 hours accounting for $21.05 \%$ (Table 2 ).

Table-2: Time since poison consumption to arrival at casualty.

\begin{tabular}{|l|l|l|l|}
\hline \multicolumn{1}{|c|}{ Time } & \multicolumn{1}{|c|}{ Number of cases } & \multicolumn{1}{c|}{ Percentage } & Mortality \\
\hline$<1$ hour & 21 & 15.67 & 0 \\
\hline $1-4$ hours & 82 & 61.19 & 0 \\
\hline $4-12$ hours & 23 & 17.16 & 0 \\
\hline$>12$ hours & 8 & 5.97 & $37.5 \%$ \\
\hline
\end{tabular}

The duration of hospital stay ranged from 1-22 days (Mean 4.49 days). 42 cases (31.34\%) stayed in the hospital for $0-2$ days. 54 cases $(40.3 \%)$ stayed for 2-4 days, 26 cases (19.4\%) stayed for 4-6 days and 12 cases $(8.96 \%)$ stayed for more than 7 days (Table 3). The duration of stay was more for snakebite and kerosene ingestion cases with complications.

Table-3: Duration of hospital stay.

\begin{tabular}{|l|l|l|}
\hline \multicolumn{1}{|c|}{ Duration } & \multicolumn{1}{c|}{ Number of cases } & \multicolumn{1}{c|}{ Percentage } \\
\hline $0-2$ days & 42 & 31.34 \\
\hline $2-4$ days & 54 & 40.3 \\
\hline $4-6$ days & 26 & 19.4 \\
\hline$>7$ days & 12 & 8.96 \\
\hline
\end{tabular}

Table 4 demonstrates, most common symptoms at the time of presentation, vomiting being the most common symptom noted in 37 cases accounting for $27.61 \%$, followed by pain and swelling at a local area in 19 cases (14.18\%), Respiratory distress in 16 cases (11.94\%), Pain abdomen in 12 cases $(8.96 \%)$ and Fever in 11 cases $(8.21 \%)$.
Table-4: Common symptoms in patients with poisoning.

\begin{tabular}{|l|l|}
\hline \multicolumn{1}{|c|}{ Symptom } & \multicolumn{1}{|c|}{ No of patients (\%) } \\
\hline Vomiting & $37(27.61)$ \\
\hline Pain and swelling at the local area & $19(14.18)$ \\
\hline Respiratory distress & $16(11.94)$ \\
\hline Pain abdomen & $12(8.96)$ \\
\hline Fever & $11(8.21)$ \\
\hline Altered sensorium & $5(3.73)$ \\
\hline Giddiness & $4(2.99)$ \\
\hline Oral burns & $4(2.99)$ \\
\hline Headache & $3(2.24)$ \\
\hline Oliguria & $2(1.49)$ \\
\hline Seizures & $2(1.49)$ \\
\hline Excess salivation & $2(1.49)$ \\
\hline Cyanosis & $2(1.49)$ \\
\hline Hypotension & $1(0.75)$ \\
\hline Ataxia & $1(0.75)$ \\
\hline Asymptomatic & $13(9.7)$ \\
\hline
\end{tabular}

Thirteen patients $(9.7 \%)$ patients remained asymptomatic and were discharged after 48 hours of observation. All cases were admitted in ICU and mechanical ventilation was required in 4 cases ( 3 snakebite cases and 1 kerosene poisoning case).

Since $54 \%$ of cases were that of snakebite and petroleum ingestion, gastric lavage was done only in 53 patients (39.55\%) and the specific antidote was given for 19 cases (14.18\%). Three patients (2 snake bite and 1 rodenticide child) died. The outcome of poisonings, stings, and bites is shown in Figure 2.

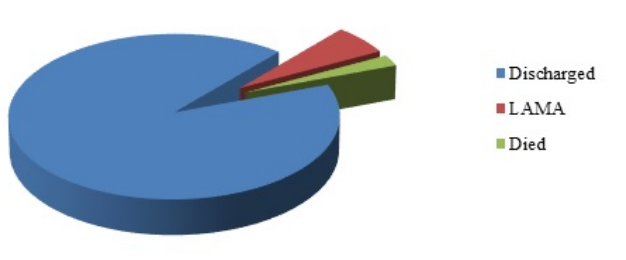

Fig-2: Outcome of poisonings, stings, and bites. 


\section{Discussion}

Hospital statistics reported periodically from different parts of the country indicate that the proportion of poisoning varies from $0.33 \%$ to $7.64 \%$ of total admissions [4]. The proportion in the present study was $2.84 \%$.

Akin to experience published from the poison control center, New Delhi [14], a major proportion $(47.01 \%)$ of affected children were $<5$ years in age. This age group is vulnerable to household accidental poisoning due to inquisitive nature, oral exploratory nature, and recently acquired mobility and hand skills. Several other experiences from India have shown similar results $[3,5,15]$. Suicidal tendencies were seen as early as 8 years in the present study. The most probable reasons might be due to the influence of television and social media.

Similar to previously published experience, from India $[16,17,18]$ and other countries across the globe $[19,20]$, it was also seen that a relatively higher proportion of boys $(61.2 \%)$ than girls with male to female ratio of 1.58 . Even though it was observed that the overall male predominance in the present study, there is a female predominance observed in the age group between 5-10 years.

The majority of the children were from a rural background as our hospital even though it is located in the urban area, being district government hospital caters to a large rural population. Most of the poisoning has occurred at home in the present study. The average time to presentation after consumption of the poison was less than $1 \mathrm{hr}$ for urban patients, who presented earlier than our rural patients. This could be explained by the longer distance that these rural patients traveled to reach our center and also by the fact that most of these patients received initial treatment at a primary health care center, before being referred to our center. Time is taken to reach an emergency since poison consumption is very important. Because early intervention better is the outcome. Three patients who died in the present study had arrived after 12 hours.

Most cases of poisoning in children $<6$-year-old are accidental in nature in contrast to adolescents in which itis more often deliberate self-poisoning (suicidal) [21-25]. This fact was reaffirmed by our data which showed that $98.41 \%$ and $71.43 \%$ of our poisoning cases in these age groups were accidental and suicidal in nature respectively.
Ten cases of suicidal poisoning had a history of parents scolding them and 2 cases had a history of the fight with siblings for a trivial reason. A countrywide estimate suggests about 10,000 suicides deaths in children between 5-14 years of age [26]. The reason for this could be anything ranging from poor school performance, bullying in school, failed relationships, conflict with parents, drug abuse, emotional insecurity, to associated psychological conditions such as depression, anxiety, etc.

Animal bites and stings $(27.61 \%)$, petroleum products $(26.87 \%)$, Household chemicals $(15.67 \%)$, and medications $(11.19 \%)$ were the most commonly identified agents of poisoning in the present study. Three most common individual agents were snake bite ( 23 cases), paint thinner (18 cases), and kerosene (13 cases). Other studies have reported Kerosene as the most common poisoning agent $[6,18,27]$.

Unlike in other studies in different parts of the country, the present study has revealed that snakebite envenomation is the commonest mode of acute poisoning. The geographical terrain of Shivamogga is the reason. The reasons for paint thinner and kerosene poisoning are summer season, festive season, painting work in house and children consume these mistaking it for water or colored drinks. Ratol (rodenticide, 3\% yellow phosphorous) is available in every provision stores and children consume this mistaking it for toothpaste.

Analysis of 2002 WHO mortality data suggests that snakebite contributes to $35 \%$ of all child deaths, globally, from venomous bites and stings, with boys about twice as likely to suffer as girls [28]. The recent community health and injury surveys in Asia show that snakebite-related injury ranks as a leading cause of childhood morbidity and mortality in this region [29]. Shivamogga has recorded the highest snake bites (930) in 2019 in Karnataka [30].

In the present study, 2 cases of cobra bite died because of late arrival to the hospital and initially treated by traditional healers. Snakebite is a widespread and previously poorly-documented global injury problem, in which children and young people are disproportionately represented. Lowincome and middle-income countries, particularly the rural areas, are the most affected. Most deaths and serious consequences from snakebites are entirely preventable by existing means, including 
Making antivenom much more widely available. Better surveillance and reporting are necessary to assess the extent of this forgotten injury and to improve prevention strategies [10]. As play is an integral part of the child's life, most of the bite occurs during play or while doing household work. Due to low educational status and high family workload, children remain unobserved during playing and therefore more prone to such accidental bites. Exploratory nature of behavior in children with no sense of fear is also a contributory factor.

Symptomatology observed closely reflected the route of a toxic ingestion. Common symptoms noted in decreasing order of frequency were vomiting; pain and swelling at the bite site, respiratory distress, abdominal pain, fever, and altered sensorium. Inherent toxicity of substances commonly consumed by our patients could possibly explain these findings.

The mortality rate in the present was $2.24 \%$ which is well in range with other national studies. In India, the reported figures for fatal poisonings ranged between $0.6 \%$ and $11.6 \%$, while in Viet Nam the reported case fatality rate was $3.3 \%[12,31]$. There is a scope to reduce mortality rate as only $76 \%$ of children reported early (within 4 hours) to hospital and $20.89 \%$ had received primary emergency care before being referred to our tertiary center.

\section{Limitations}

The study was conducted in Shivamogga district government hospital which receives sick patients from surrounding 7 districts and has more than 1000 PICU admissions per year; hence the conclusions of the study can be extrapolated to large populations.

\section{Conclusion}

Accidental poisonings are common in children below 5 years of age when parents are less attentive. The age range of suicidal poisoning is widening, as low as 8 years. Mortality and morbidity are high in cases of delayed treatment. The most common agent implicated is snake bite. Parental education regarding poison proofing a child's environment and guidance at every school to help children deal with stressful situations would be apt preventive measures. The most important step is to bring the child to the hospital at the earliest to reduce the morbidity and mortality significantly.

\section{What does this study add to the existing knowledge?}

Snakebite cases are more common than kerosene and turpentine poisoning with high mortality. Awareness among the community for the avoidance of traditional treatment and to seek early medical intervention in snake bites is essential.

\section{Author's contributions}

Dr. Vijayalakshmi P.: Data collection and Manuscript Preparation

Dr. Shreeshail v. Benakanal: Manuscript preparation

Dr. Ravindra B. Patil: Statistical analysis

Dr. Manoj GM: Statistical analysis

Dr. R. Vikram S. Kumar: Statistical analysis

\section{Reference}

01. Reddy KS, Murthy OP. The essential of forensic medicine and toxicology. India- Medical Book Comp.

[Crossref]

02. Lozano R, Naghavi M, Foreman K, Lim S, Shibuya K, Aboyans V, et al. Global and regional mortality from 235 causes of death for 20 age groups in 1990 and 2010- a systematic analysis for the Global Burden of Disease Study 2010. The Lancet. 2012;380(9859)2095-2128.

doi: $10.1016 / \mathrm{S} 0140-6736(12) 61728-0$ [Crossref]

03. Brata Ghosh V, Jhamb U, Singhal R, Krishnan R. Common childhood poisonings and their outcome in a tertiary care center in Delhi. Indian J Pediatr. 2013;80(6)516-518.

doi: $\quad 10.1007 / \mathrm{s} 12098-012-0879-5 \quad$ [Crossref]

04. Roy RN, Shrivastava P, Das DK, Saha I, Sarkar AP. Burden of hospitalized pediatric morbidity and utilization of beds in a tertiary care hospital of Kolkata, India. Indian $\mathrm{J}$ Comm Med. 2012;37(4)252.

[Crossref]

05. Jayashree $M$, Singhi S. Changing trends and predictors of outcome in patients with acute poisoning admitted to the intensive care. J Trop Pediatr. 2011;57(5)340-346.

[Crossref:Crossref] 
06. Kohli U, Kuttiat VS, Lodha R, Kabra SK. Profile of childhood poisoning at a tertiary care centre in North India. Indian J Pediatr. 2008;75(8)791. [Crossref]

07. Budnitz DS, Lovegrove MC. The last mile- taking the final steps in preventing pediatric pharmaceutical poisonings. J Pediatr. 2012; 160(2)190-192.

[Crossref]

08. Suvedi BK. A retrospective study of poisoning cases at Bir Hospital, Nepal. J Inst Med. 1990;12;296-302.

[Crossref]

09. Lall SB. Accidental pediatric poisoning--a preventable medical emergency. Indian J Pediatr. 1998;65(3)363-364.

[Crossref]

10. Branche C, Ozanne-Smith J, Oyebite K, Hyder AA. World report on child injury prevention. World Health Organization. 2008;123-142.

[Crossref]

11. Singh S, Singhi S, Sood NK, Kumar L, Walia BN. Changing pattern of childhood poisoning (19701989)- experience of a large north Indian hospital. Indian Pediatr. 1995;32;331.

[Crossref]

12. Dutta AK, Seth $A$, Goyal PK, Aggarwal V, Mittal SK, Sharma R, Bahl L, Thakur JS, Verma M, Chhatwal J, Chacko B. Poisoning in children: Indian scenario. Indian J Pediatr. $1998 ; 65(3) 365-370$.

[Crossref]

13. Desalew M, Aklilu A, Amanuel A, Addisu M, Ethiopia T. Pattern of acute adult poisoning at Tikur Anbessa specialized teaching hospital, a retrospective study, Ethiopia. Human Experiment Toxicol. 2011;30(7)523-527.

[Crossref]

14. Gupta SK, Peshin SS, Srivastava A, Kaleekal T. A study of childhood poisoning at national poisons information centre, All India Institute of Medical Sciences, New Delhi. J Occupational Health. 2003;45(3)191-196.

[Crossref]

15. Balan B, Lingam L. Unintentional injuries among children in resource poor settings- where do the fingers point. Arch Dis Childhood. 2012;97(1)35-38.

[Crossref]
16. Sharma A, Dishant VG, Kaushik JS, Mittal K. Aluminum phosphide (celphos) poisoning in children- A 5-year experience in a tertiary care hospital from northern India. Indian $\mathrm{J}$ Critical Care Med. 2014;18(1)33.

[Crossref]

17. Singh SP, Aggarwal AD, Oberoi SS, Aggarwal KK, Thind AS, Bhullar DS, et al. Study of poisoning trends in north India-a perspective in relation to world statistics. J Forensic Legal Med. 2013;20(1)14-18.

[Crossref]

18. Gupta S, Govil YC, Misra PK, Nath R, Srivastava $\mathrm{KL}$. Trends in poisoning in children- experience at a large referral teaching hospital. Nat Med J India. $1998 ; 11 ; 166-168$.

[Crossref]

19. Sinno D, Majdalani M, Chatila R, Musharrafieh U, Al?Tannir M. The pattern of self?poisoning among Lebanese children and adolescents in two tertiary care centres in Lebanon. Acta Paediatrica. 2009;98(6)1044-1048.

[Crossref]

20. Franklin RL, Rodgers GB. Unintentional child poisonings treated in United States hospital emergency departments- national estimates of incident cases, population-based poisoning rates, and product involvement. Pediatr. 2008;122(6)1244-1251.

[Crossref]

21. Rodgers GC, Matyunas NJ, Poisonings- Drugs, chemicals, and plants. Nelson Textbook of Pediatrics; Editors- Behrman RE, Kliegmen RM, Jenson HB. WB Saunders. Philadelphia.

2004;2362-2374 [Crossref]

22. Srivastava A, Peshin SS, Kaleekal T, Gupta SK. An epidemiological study of poisoning cases reported to the national poisons information centre, All India Institute of Medical Sciences, New Delhi. Human \& experimental toxicology. 2005 Jun;24(6)279-85.

doi: $\quad 10.1191 / 0960327105$ ht527oa $\quad$ [Crossref]

23. Alazab RM, Elmougy MT, Fayad RA, Abdelsalam $\mathrm{HF}$, Mohamed AS. Risk factors of acute poisoning among children- a study at a poisoning unit of a university hospital in Egypt. South East Asia J Public Health. 2012;2(2)4147.

[Crossref] 
24. Gauvin F, Bailey B, Bratton SL. Hospitalizations for pediatric intoxication in Washington State, 1987-1997. Arch Pediatr Adol Med. 2001;155(10)1105-1110.

[Crossref]

25. Paudyal BP. Poisoning- pattern and profile of admitted cases in a hospital in central Nepal. JNMA J Nepal Med Assoc. 2005;44(159)92-96. [Crossref]

26. Gajalakshmi V, Peto R. Suicide rates in rural Tamil Nadu, South India- verbal autopsy of 39,000 deaths in 1997-98. Int J Epidemiol. 2007;36(1)203-207.

[Crossref]

27. WHO. mortality database- tables. Geneva, World Health Organization. Accessed on July 20, 2020. Available at [Article:https://apps.who.int/healthinfo/statistics/mor tality/whodpms/params_ex.php][Crossref]
28. Venkatesh C, Sriram P, Adhisivam B, Mahadevan S. Clinical profile of children with kerosene aspiration. Tropical Doc. 2011;41(3)179-180. [Crossref]

29. Linnan M, Pham VC, Rahman F, Rahman A, Shafinaz S, Sitti-Amorn $C$, et al. Child mortality and injury in Asia- survey results and evidence Innocenti Working. Innocenti Research Centre. Papers, No 2007/06.

[Crossref]

30. National Health Profile. 2019. Available at https://www. thehinducentre.

com/resources/article29841374.ece/binary/86033216 91572511495.pdf. Accessed on July 202020 [Crossref]

31. Du NT, Due B, Due P. Epidemiology of acute poisonings in Vietnam. J Toxicol Clin Toxicol. $2001 ; 39 ; 527-528$.

[Crossref] 